\title{
A LEITURA NA PERSPECTIVA DISCURSIVA: O POLÍTICO E A POLÍTICA EM CHARGES
}

\author{
JOSÉ CARLOS MOREIRA ${ }^{1}$ \\ MARIA CLECI VENTURINI ${ }^{2}$
}

Programa de Pós-graduação em Letras

Universidade Federal do Paraná

Rua General Carneiro, 460 - Centro - Curitiba - PR - Brasil

Programa de Pós-graduação em Letras

Universidade Estadual do Centro-Oeste

Rua Pe. Salvatore Renna, 857 - Guarapuava - PR - Brasil

jcarlosmoreira7@gmail.com, mariacleciventuriniegmail.com

\begin{abstract}
Resumo. A Análise de Discurso, como disciplina de entremeio, considera diferentes domínios do saber e seu objeto de análise é o discurso como efeito de sentidos entre interlocutores. Metodologicamente, a questão de pesquisa determina os dispositivos teóricos-metodológicos a serem mobilizados nas análises. Neste artigo, a charge é a materialidade significante pela qual buscamos analisar o discurso político que circulou no período que antecedeu a reforma da previdência, em 2019. As análises incidem sobre três charges $e$, a partir delas, buscamos compreender como a resistência a acontecimentos que afetam as práticas sociais é discursivizada e que memórias e discursos outros ressoam, instaurando a resistência pela língua na história.
\end{abstract}

Palavras-chave: materialidade significante; lingua; sujeito; ideologia; discurso político.

Résumé. L'analyse du discours, en tant que discipline interprétative à part entière, considère différents domaines de la connaissance et son objet d'analyse est le discours comme effet du sens entre interlocuteurs. Méthodologiquement, la question de recherche détermine les dispositifs théorico-méthodologiques à mobiliser dans les analyses. Dans cet article, la caricature est la matérialité discursive par laquelle nous cherchons à analyser le discours politique qui a circulé dans la période précédant la réforme des retraites, en 2019. Les analyses se concentrent sur trois caricatures et à partir de celles-ci nous cherchons à comprendre comment la résistance aux événements qui affectent les pratiques sociales est discursivisée et quelles mémoires discursives et des discours autres résonnent, établissant une résistance par la langue dans l'histoire.

\footnotetext{
${ }^{1}$ Doutorando do Programa de Pós-graduação em Letras (UFPR).

${ }^{2}$ Doutorado em Letras (Estudos Linguísticos, pela UFSM); Estágio Sênior na Universidade de Coimbra, sob a supervisão de Fernando Catroga. Bolsista Produtividade da Fundação Araucária. Docente dos Programas de Pós-graduação em Letras da UNICENTRO e da UFPR.
} 


\author{
Mots-clés: matérialité discursive; langue; sujet; idéologie; discours \\ politique.
}

\title{
PRIMEIRAS PALAVRAS
}

Nossa proposta, com este artigo, é ler a política e o político em charges, tomandoas como materialidades significantes que "olham" criticamente para os acontecimentos que circulam como discurso, na formação social. Assim como Herbert ([1966] 2011), não pretendemos que a política se reduza ao discurso, mas que funcione como uma prática e que essa prática se torne visível pelo que circula na formação social e pelos modos como a língua é mobilizada, constituindo efeitos de sentidos. Há que se destacar, entretanto, que o político e a política são presença em todo o discurso, tendo em vista que a discursivização sempre se dá pelo político, considerando-se que, conforme Orlandi (2011), a realização do exercício discursivo implica tomada de posição, sinalizando para a não-neutralidade.

A filiação à Análise de Discurso, a partir de Pêcheux, Orlandi e pesquisadores que comungam da teoria, decorre de uma tomada de posição, pela qual concebemos a leitura como prática política. Assim como o autor, o leitor lê/interpreta/compreende as materialidades discursivas e, a partir de sua filiação em formações discursivas, realiza gestos, segundo Orlandi (2004, p. 18), como "um ato no nível do simbólico". Para a autora, a "palavra gesto, na perspectiva discursiva, desloca a noção de 'ato' da perspectiva pragmática, sem no entanto, desconsiderá-la". Isso significa que o sujeito-leitor, diante de um texto, unidade de análise do discurso, assume uma posição-sujeito dentro da formação social. Nessa perspectiva, a leitura "não é transparente e 'a relação entre os diferentes autores' vai constituindo a ciência, dando visibilidade 'à necessidade de resignificação', apresentando-se a leitura como aparato teórico" (ORLANDI, 2004, p. 41).

Na Análise de Discurso, ressoa forte a aproximação da interpretação e das relações de sentidos que possibilitam ler/interpretar/compreender, adentrando a opacidade do texto. Entendemos a partir de Pêcheux (1997a, p. 160) que o sentido das palavras

[...] não existe 'em si mesmo' (isto é, em sua relação transparente com a literalidade significante), mas ao contrário, é determinado pelas posições ideológicas que estão em jogo no processo sócio-histórico, no qual as palavras, expressões e proposições são produzidas (isto é, reproduzidas).

Destacamos, desse modo, que a leitura discursiva depende de sujeitos, de suas filiações e do espaço político em que as palavras se movimentam a partir de processos discursivos e que a relação entre textos, sujeitos e memória não se refere à intertextualidade, mas à interdiscursividade.

Nosso objetivo, com este texto, é analisar o discurso político que circulou no período que antecedeu a reforma da previdência, em 2019. Para atender a esse objetivo, elegemos a charge enquanto materialidade que significa "como modo significante pelo qual o sentido se formula" (LAGAZZI, 2010, p. 173). A charge, como materialidade significante, pode ser definida como um dos artefatos de leitura pelo qual as palavras, as 
imagens e os acontecimentos, decorrentes de práticas sociais e de circulação de discursos entre sujeitos, instauram efeitos de sentidos pelo trabalho da língua na história. Esses efeitos são constituídos a partir de processos discursivos, definidos por Pêcheux (1997a, p. 161) "como o sistema de relações de substituição, paráfrases, sinonímias etc., que funcionam entre elementos linguísticos - 'significantes' - em uma formação discursiva dada".

Propomos analisar três materialidades, retiradas de sites do ambiente virtual. A Charge 1, circulou em 22 de março de 2019, por ocasião da luta contra a reforma da previdência, no site Sinergiabahia, que pertence ao sindicato dos eletricitários da Bahia. A estrutura desta charge se dá a partir de duas palavras: neoliberalismo e previdência, sendo que a primeira tem como arma uma bota, que pisa e pressiona, esmagando a previdência. As Charges 2 e 3 foram publicadas em um site de imagens do Google e, cumprindo um dos funcionamentos da charge, fazem críticas ao momento político, ocupam-se da política nesse período. Na segunda textualidade, há um jogo de palavras que instaura equívocos por encaminhar para diferentes domínios, destacando-se um positivo e outro negativo. A crítica social faz referência aos sujeitos que nascerão, após a reforma, sem direitos. A terceira concerne aos 'fatiamentos', encaminhando para cortes, matando a previdência e com ela os sujeitos. As charges enfocam a reforma da previdência e têm como particularidade a repetição pela qual ressoa a prática política e, por estar constantemente na mídia, abrem para a resistência, considerando as implicações sociais, políticas e econômicas da reforma nas futuras aposentadorias ${ }^{3}$.

O texto divide-se em duas partes, além das primeiras palavras e considerações finais. Na primeira parte, empreendemos discussões sobre a Análise de Discurso e sobre o modo como dentro desse campo teórico a leitura centra-se na interpretação e na produção de efeitos de sentidos a partir de sujeitos, inscritos em determinadas formações discursivas e das condições de produção do discurso. Na segunda parte, buscamos definir a charge e verificar o seu funcionamento discursivo como resistência. Nessa segunda parte, vamos realizando o movimento teórico e analítico, tendo em vista a não separação entre teoria e prática e o destaque para a prática analítica, decorrente de um movimento pendular, conforme Petri (2013, p. 40), trazendo "os sentidos mesmo do pêndulo, enquanto objeto material que tem uma história e constitui a historicidade de diferentes áreas do conhecimento [...]". Resumidamente, a autora mobiliza "esse movimento de vaivém, produzido pelo pêndulo", marcando a ida ao corpus e o retorno constante à teoria.

\section{SOBRE A ANÁLISE DE DISCURSO E OS DISPOSITIVOS TEÓRICOS- METODOLÓGICOS}

De acordo com Orlandi (2004, p. 13), a AD é uma disciplina de interpretação. Isso significa compreender o processo discursivo e, a partir dessa compreensão, destacar o funcionamento deste conceito que "problematiza a atribuição de sentido(s) ao texto". O desafio do analista de discurso, nessa perspectiva, não é buscar conteúdos, mas interpretar, entendendo por interpretação a compreensão e a produção de sentidos do texto como "um bólido de sentidos", que parte em "inúmeras direções, em múltiplos planos significantes" (ORLANDI, 2004, p. 14). A transformação do objeto empírico em objeto

\footnotetext{
${ }^{3}$ Para saber mais sobre a previdência, consultar o site: <https://administradores.com.br/artigos/analisecritica-a-proposta-da-reforma-da-previdencia >. Acesso em: 10 abr. 2020.
} 
discursivo é um dos passos importantes para realizar as análises. Nas palavras de Pêcheux (1997a) e de Orlandi (2002), é a passagem do objeto linguístico para o objeto discursivo. Com isso, a preocupação com o texto 'original' ou com a 'verdade' apaga-se, pois se trata sempre de "vários, desde sua 'origem', os textos possíveis num mesmo texto" (ORLANDI, 2004, p. 14).

Metodologicamente, a leitura analítica demanda a construção de um dispositivo de interpretação, o qual, de acordo com Orlandi (2004, p. 59), objetiva

[...] o dito em relação ao não dito, o que o sujeito diz de um lugar com o que é dito em outro lugar, o que é dito de um modo com o que é dito de outro, procurando ouvir naquilo que o sujeito diz, o que ele não diz mas que constitui igualmente os sentidos de suas palavras [...].

Vale sublinhar, ainda, a partir de Orlandi (2002, p. 59), a preocupação do analista não com a verdade, mas com "o real do sentido em sua materialidade linguística e histórica". Cabe ao sujeito interpretar e, para alcançar esse objetivo, realiza a escuta discursiva pela qual descreve os gestos de interpretação, dando visibilidade à ligação existente entre os processos de identificação e as memórias que possibilitam esses processos. Desse modo, conforme Orlandi (2002, p. 60), "descrição e interpretação se interrelacionam".

O dispositivo de interpretação, segundo a mesma autora, tem como um de seus mecanismos a alteração da posição-sujeito leitor para o lugar da alteridade, construído pelo analista. Nesse lugar, a alteridade do cientista e as possíveis leituras pelas quais o sujeito se inscreve no lugar do analista e constrói o lugar teórico, dependem não só da literalidade, mas também da ideologia. Desse lugar, o sujeito "não reflete, mas situa, compreende, o movimento de interpretação inscrito no objeto simbólico que é seu alvo. Ele pode, então, contemplar (teorizar), expor, "descrever os efeitos de interpretação", (ORLANDI, 2002, p. 61). Disso, podemos sublinhar que o analista trabalha nos limites da interpretação e não busca os sentidos do texto, nem se coloca fora da história, do simbólico e da ideologia. Pelo contrário, ele se inscreve em uma posição deslocada e, dessa posição, busca analisar como os efeitos de sentidos se constituem, por quais processos discursivos e em que condições de produção.

Como campo disciplinar, a AD se realiza por e a partir de sujeitos, de modo que as análises encaminham para diferentes leituras, mesmo que se trate de uma mesma materialidade significante, o que não ocorre nas ciências positivistas. A textualidade discursiva é aberta, o significado é incompleto e acena para rupturas, equívocos, contradições, não-ditos, mostrando que os sentidos "não se fecham, não são evidentes, embora pareçam ser" (ORLANDI, 2004, p. 9). Destacamos, por isso, que as análises reclamam diferentes domínios de saber, fazendo com que o trabalho da ideologia se realize pela língua na história, abrindo para o simbólico e este para o equívoco. É importante, antes de continuar, sinalizar junto com Orlandi (2004, p. 10) que: 1) a interpretação está em todos os sujeitos; 2) as instituições regulam os sentidos e estes dependem de quem, como e em que condições de produção a materialidade discursiva se formula e faz circular as memórias mobilizadas; 3) a interpretação é singular e torna visível as diferenças entre os analistas. 
Vale sublinhar, portanto, a relevância da inscrição dos sujeitos em formações discursivas, tendo em vista que o dizer é determinado pelas posições-sujeito em funcionamento. Nesse sentido, consideramos os indivíduos e a sua interpelação pelo complexo das formações ideológicas, pelo/a partir do interdiscurso, que "fornece a cada sujeito sua realidade enquanto sistema de evidências e de significações percebidas aceitas - e experimentadas" (PÊCHEUX, 1997a, p. 162). O dizer, nesse funcionamento, não é isento de filiações e de comprometimentos, demandando daí a inclusão do político e da política, considerando as escolhas linguísticas, os processos discursivos e o posicionamento do sujeito, interpelado pela ideologia e atravessado pelo inconsciente. Há determinados discursos que retornam, se repetem, são refutados ou não chegam a se 'inscrever', como nos ensina Pêcheux (1999). O mesmo autor (2002, p. 53) sinaliza para a provisoriedade dos sentidos e para a sua não-homogeneidade, assinalando que "todo o enunciado é intrinsecamente suscetível de tornar-se outro, diferente de si mesmo, de se deslocar discursivamente de seu sentido para derivar para um outro [...], oferecendo lugar à interpretação". Demanda dessas reflexões sublinhar, conforme assevera Orlandi (2004, p. 60), o não batimento entre texto e discurso.

No que se refere ao discurso, Pêcheux (2002) mobiliza a estrutura (sistema) e o acontecimento (historicidade), considerando materialidades significantes que conjugam, conforme Orlandi (2001), a constituição, a formulação e a circulação. Nesse sentido, a constituição diz respeito à memória do dizer e faz interferir o contexto históricoideológico, como condições de produção no sentido amplo, abrangendo as relações sóciohistóricas e o que circulou antes, em outro lugar. Já a formulação se dá em condições de produção e em circunstâncias de enunciação presentes no texto, mas não necessariamente dentro do texto, devido ao funcionamento constitutivo da exterioridade, da memória e dos discursos que retornam. A circulação reporta ao suporte em que a materialidade significante está posta e faz parte da interpretação, uma vez que o mesmo dizer significa diferentemente, dependendo de quem o publica e onde ele é publicado ou dito.

É nesse processo "do dito e do não dito" que se configura o interdiscurso, abrindo espaço para a ideologia e sinalizando que os sentidos se constituem a partir da filiação dos sujeitos em formações discursivas (FD). Com isso, a exterioridade intervém e instaura a textualidade, por meio de memórias que se entrelaçam, mas deixam furos e, desse modo, tecem relações, dando visibilidade ao tecido da memória e à instauração da discursividade. Trata-se, portanto, de sublinhar a exterioridade, tendo em vista que "é no discurso que o homem produz a realidade com a qual ele está em relação" (ORLANDI, 2004, p. 39). O exterior, o fora que é dentro, funciona nos processos de formulação do texto, mas também pela memória, pelos pré-construídos e pela constituição e circulação do texto, conforme referido anteriormente.

O exercício analítico empreendido, neste texto, se realiza pelo movimento pendular de ida e de volta do corpus para a teoria. Propomos, a partir desse movimento pendular (PETRI, 2013), a realização de gestos analíticos, por meio de charges, considerando as condições de produção de um tempo próximo, ainda não historicizado, como a reforma da previdência proposta pelo governo federal, aprovada no final de 2019. Ainda que as charges tenham sido publicadas antes da reforma da previdência, elas problematizaram criticamente o acontecimento, discursivizando textualidades que deslocam e colocam em suspenso as consequências dessa aprovação para os aposentados. De acordo com Baronas e Aguiar (2009, p. 166), "a charge se interessa pela relação de 
sentidos que se estabelece entre o acontecimento histórico e o acontecimento discursivo dado a circular". Como materialidade significante, desconstrói as regularidades por meio de recursos linguísticos e visuais, que funcionam discursivamente como um exercício de resistência aos acontecimentos que afetam a formação social e, principalmente, os mais vulneráveis. Com isso, desnuda a luta de classes e, no discurso pré-reforma da previdência, a vida dos futuros aposentados. Vale destacar, assim, os modos como a resistência constitui efeitos de sentidos e instaura o equívoco, a contradição e, muitas vezes, o antagonismo.

A charge, como materialidade significante, trabalha com o humor, recriando o acontecimento pela repetição, por deslocamentos e pela instauração de equívocos no investimento da língua na história. Nesta discursividade, as imagens se fazem em (dis)curso e por elas ressoa o já significado antes, em outros lugares. As memórias, que também ressoam, por sua vez, instauram contradições, significando-se como um dos principais mecanismos do emprego do humor na perspectiva discursiva. Mesmo que não aposte no novo, a charge dá visibilidade ao modo como o discurso significa pela inscrição de sujeitos em lugares de fala, já referidos anteriormente, por funcionamentos da memória, pela qual retorna a história, como historicidade, pelo sujeito historicamente constituído.

Pelo jogo da língua no simbólico e pelas práticas sociais que se constituem por esse jogo, é possível discutir e problematizar o que afeta a vida da formação social e as relações entre sujeitos. Nessa materialidade, ressoa e faz sentido o discurso de resistência, que incide sobre acontecimentos e sobre lugares de poder, questionando práticas ou referendando-as, desnudando ou apagando a manipulação. A constituição, formulação e circulação destas materialidades constituem efeitos de luta e de resistência às práticas contrárias aos anseios da formação social, ressoando forte a perda de direitos já adquiridos. Essas práticas podem apagar o estado de direito e instaurar práticas cada vez mais totalitárias, ocasionando o aumento da exploração, enfim, esvaziando a luta de classes.

Em sua formulação, a charge sustenta-se em diferentes discursos, sobretudo, em notícias veiculadas por jornais impressos e por outros meios de comunicação. É assim que o discurso de humor político se constitui por gestos de interpretação (ORLANDI, 2005, 2002, 1996), que mexem com as evidências ideológicas, com as estruturas já postas e rompem com as regularidades. Isso ocorre pelo jogo linguístico e pelas possibilidades criadas por processos discursivos, os quais são permitidos/sustentados pela língua na história, que não é linear, nem fechada.

Quando a charge é mobilizada/significada pela intervenção da língua na história, ela não apenas provoca o riso, mas também faz funcionar a crítica social em relação ao que ocorre na formação social em termos de práticas políticas. Nesse sentido, a memória e a história sustentam e legitimam o discurso, ressignificam crises do passado, constituem versões para o presente e dão visibilidade ao presente bem localizado e ao futuro - que é interpretado por um passado em um tempo mais atual, sinalizando para o que pode ocorrer, a partir de um acontecimento que, no presente, aumenta tensões, equívocos, questionamentos e resistências. A charge aparece preferencialmente na mídia, conforme Aguiar (2009), incluindo em sua textualização a imagem como materialidade discursiva que circula na formação social, produzindo a diferença, mesmo no que se repete. Como 
materialidade discursiva, a charge trabalha na desconstrução de imaginários sociais, provocando menos o riso e mais a crítica social, ancorando-se em discursos vindos de domínios distintos e tomando como ponto nodal acontecimentos, centrados em notícias veiculadas em jornais e na mídia em geral.

O toque de humor irreverente, crítico, que parece ser inofensivo, expõe o cotidiano da formação social com suas mazelas, experiências, misérias, fraquezas, valores e grandezas humanas (FLÔRES, 2002). Nas charges, as práticas sociais articulam-se no entremeio do verbal e do não-verbal (texto e imagem), destacando-se, em sua constituição, como materialidade a metáfora, a metonímia, a ironia e a caricatura, entre outros discursos linguísticos. A charge, assim como outras materialidades que circulam na formação social, "jamais é inocente". Serve-se de já-ditos para instaurar o novo e romper com redes parafrásticas, destacando entre seus jogos cênicos, o batimento e o não batimento da língua pelo dito e pelo não-dito. Pode, dessa forma, instaurar o novo ou reproduzir o já-dito e significado. É possível sublinhar, então, que a charge constitui-se de linguagem, segundo Pêcheux (1997b), como um fenômeno relacionado ao interior de sua materialidade, enquanto forma linguística, e com o seu exterior, o que está fora e retorna pela memória como pré-construído.

Trata-se de um discurso, cuja materialidade ultrapassa a língua em movimento, o que é próprio do linguístico. Segundo Pilla e Quadros (2009, p. 10), é uma materialidade que prima pelo exagero nos traços "e na síntese dos fatos". Com isso, faz críticas a sujeitos, a fatos ou a acontecimentos políticos, com o objetivo de atingir determinados fins, dentre eles, as práticas sociais e as políticas de determinadas épocas.

Desse modo, conforme já destacamos, a charge vai funcionar como discurso e nela ressoam memórias e outros discursos com os quais o tempo mais próximo é identificado. Não obstante, é possível dizer que o sentido não está posto de modo estanque, mas como efeito do trabalho do simbólico sobre a cadeia significante, considerando a história como historicidade. A textualidade ${ }^{4}$, em tela, pode ser lida de acordo com as práticas e os discursos em torno da reforma da previdência, em que o Neoliberalismo retoma e dá visibilidade ao Governo e a Previdência ao povo - sujeitos coletivos.

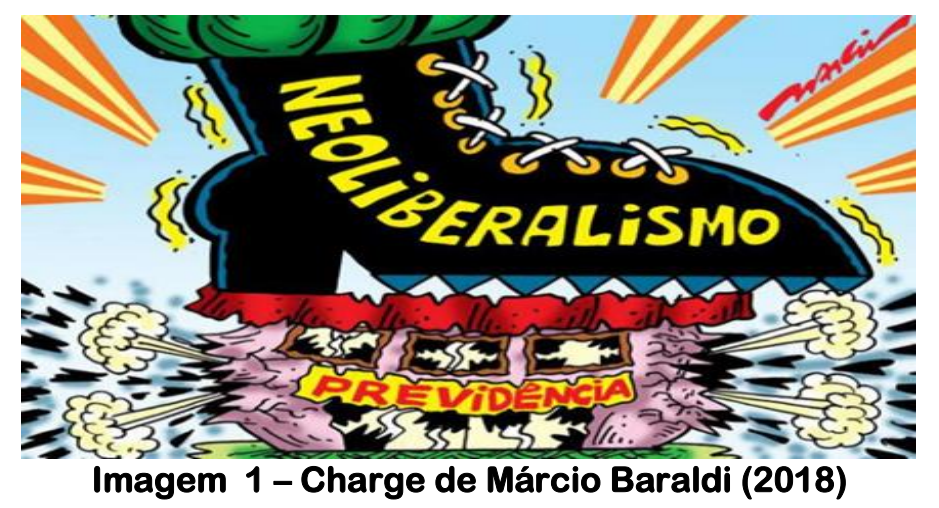

\footnotetext{
${ }^{4}$ Pode ser acessada pelo link: <https://spbancarios.com.br/10/2018/bolsonaro-quer-copiar-modelo-falidode-previdencia-do-chile>. Acesso em: 10 set. 2020.
} 
A materialidade significante, em tela, é de autoria de Márcio Baraldi, cartunista, quadrinista e documentalista brasileiro, que recebeu o prêmio Angelo Agostini, como melhor cartunista, em 04 de dezembro de 2009. A publicação foi feita em 24 de outubro de 2018, pelo Spbancários, destacando que as informações são do Jornal Folha de São Paulo.

A matéria discute a reforma da previdência, proposta por Bolsonaro, e ancora as discussões na reforma de previdência, realizada no Chile, em 1981, pelo General Augusto Pinochet. O modelo de então, continua em vigência no Chile, enquanto proposta neoliberal, que implantou o sistema de previdência privada, em que os trabalhadores destinam $10 \%$ de seus salários para uma conta de capitalização individual, sem a participação patronal.

A reforma que ocorreu no Chile e também no Japão pauta-se na não participação do Estado na economia, sinalizando para a livre concorrência, a total liberdade do comércio e, no que tange ao trabalho, a livre negociação. Trata-se de uma memória que ressoa no intradiscurso, como o que significa antes, em outro lugar, como pré-construído, fazendo retornar o já significado, que se repete, por meio de cadeias parafrásticas. Nessa repetição, o discurso não retorna de forma literal, tendo em vista as condições de produção, as posições-sujeito daqueles que leem e interpretam. De qualquer forma, tanto a materialidade construída pela charge, quanto o texto que ela 'ajuda a significar', são atravessadas pelos posicionamentos de sujeitos, não importando aos analistas, os conteúdos ou posicionamentos. As análises incidem sobre a composição da charge e quais sentidos se constituem a partir dela, pelo que está posto em (dis)curso, instaurando efeitos.

Como analistas de discurso, nos interessa a charge e o modo como o autor, inscrevendo-se em uma determinada formação discursiva, constrói efeitos de sentidos e faz uma leitura para a proposta de reforma, encabeçada pelo ministro Paulo Guedes e chancelada pelo presidente, desde a campanha para a presidência da República. Há apagamentos e transformações e, nesse caso, há - entre outros - o apagamento da desigualdade entre patrões e empregados, em que empregado e patrão são duas posiçõessujeito distintas, que até podem se inscrever na mesma formação discursiva, mas não na mesma posição-sujeito. Frequentemente, ocorre, por parte do sujeito que ocupa o lugar de empregado, uma contraidentificação, instaurando a resistência, o distanciamento, que apaga possíveis traços/laços de identificação.

Esses apagamentos instauram o equívoco presente pela simplificação das relações e das práticas sociais, por meio de regimes capitalistas e totalitários, que constituem evidências de que a reforma favorece os trabalhadores. Na charge, pela palavra LIBERALISMO, ressoa a retomada das ideias liberais em voga nos séculos XVIII e XIX, ligadas ao pensamento do economista escocês Adam Smith, considerado "o pai do Liberalismo" , do qual deriva o pensamento do neoliberalismo e a defesa da globalização. O neoliberalismo tem como pauta a política de cortes de gastos sociais, especialmente na saúde e na educação, e a diminuição dos gastos patronais e do Estado, diminuindo as instituições públicas através de privatizações. Nesse funcionamento, a Previdência aparece como vilã, por onerar o Estado, diante das aposentadorias e da longevidade dos sujeitos. A principal face do neoliberalismo é a privatização, que representa a venda ou a transferência das instituições públicas para a iniciativa privada.

\footnotetext{
${ }^{5}$ Disponível em: <https://www.sunoresearch.com.br/tudo-sobre/adam-smith/>. Acesso em: 26 abr. 2020.
} 
$\mathrm{Na}$ materialidade discursiva em análise, o neoliberalismo pode instaurar efeitos de sentidos e se constitui em (dis)curso, pela aproximação simbólica com uma bota que esmaga a previdência. Ressoa, pela bota, memórias e discursos que presentificam a reforma da previdência realizada no Chile por Pinochet, que era general, legitimando-se e aproximando-se de práticas ditatoriais, que aproximam Pinochet e Bolsonaro, enquanto militares. A crítica ocorre pela ancoragem dada pelo discurso que defende a não participação do Estado em políticas sociais, achatando a previdência e, com ela, os trabalhadores. Trata-se de uma crítica à política do governo filiado ao PSL (Partido Social Liberal - e após, sem partido), que desde a campanha eleitoral se propôs a realizar a reforma da previdência. $\mathrm{O}$ que é recorrente, na materialidade significante charge, é o alargamento dos sentidos, e isso é o que ocorre na materialidade em análise, quando a bota, além de funcionar como uma arma forte e capaz de achatar a Previdência (o povo), encaminha para efeitos de sentidos de um possível retorno do regime de exceção. A bota funciona como a metáfora pela qual retorna o regime de exceção protagonizado pelos militares, ressoando por eles a opressão e perdas. A materialidade permite significar os militares como possíveis responsáveis pelo tolhimento da liberdade do povo, exigindo silêncio e obediência, promovendo a soberania totalitária do Estado, que centra as decisões no executivo e apaga o Estado de Direito, segundo Zandwais (2009, p. 74), pela repetição de ideias e de slogans, com vistas a submeter as massas, ressoando ideias defendidas por Hitler, de acordo com o qual "as multidões não possuem nada melhor do que a capacidade repetitiva e uma memória curta $[\ldots]$ ".

Nessa materialidade significante, o Estado ocupa a posição-sujeito no contexto político brasileiro, identificando-se com a formação discursiva Liberal, que resultou no neoliberalismo, que prioriza os valores capitalistas, opondo-se ao povo, que pode ser lido pela palavra PREVIDÊNCIA. Com isso, ocorre a perda de direitos - o que se repete -, apesar de toda a luta, de manifestações, de revoltas. As perdas que ressoam nesse discurso atingem não só a aposentadoria, mas os demais direitos, dentre eles a reivindicação de reposição salarial, de aviso prévio, diminuição de salários, falta de moradia e de investimento na saúde e na educação. Essas práticas mostram o embate entre o patrão, que está do outro lado, e pode ser lido como a bota, encaminhando o sentido para distintas direções, centrando-nos na palavra NEOLIBERALISMO e na bota que impulsiona a perda de direito do povo, como representação imaginária de regimes totalitários, identificados com o Estado e, nesse caso, ocorrem desigualdades.

Assim, podemos realizar interpretações não coincidentes e que dependem da inscrição daquele que lê, interpreta e compreende. Uma das possíveis leituras dessa materialidade é a aproximação do neoliberalismo com o autoritarismo. Outra possibilidade de leitura decorre da aproximação da bota - neoliberalismo - com o regime capitalista em que as classes dominantes apagam protagonismos do povo, retirando seus direitos, sinalizando para a submissão. O cerceamento da liberdade, nessa perspectiva, não significa um regime escravagista, mas a luta de classes, em que o embate se dá entre aquele que é explorado e aquele que explora. No entanto, os sentidos não se esgotam e, para sustentarmos esse posicionamento, trazemos Pêcheux (1997a), e retomamos o funcionamento de duas representações, mobilizadas na análise da materialidade em tela.

Nessa materialidade há, de um lado, a representação do liberalismo, em que ressoam os preceitos de Adam Smith e, de outro, a representação do capitalismo. Por 
meio dessas duas representações, retornam memórias do surgimento, na Idade Média, de formações sociais que primam pelo capital privado e pela defesa do lucro. Dessas duas representações, instaura-se o que entendemos, a partir de Pêcheux (1997a), como uma terceira representação. Em nosso movimento analítico, essa terceira representação agrega o liberalismo e o capitalismo e no que retornam dessas representações, o neoliberalismo, possível de ser interpretado pela cadeia metafórica decorrente da bota, que oprime e subjuga. Nas palavras de Pêcheux (1997, p. 175), trata-se da

[...] formação de uma representação, que aparece conscientemente ligada a primeira, embora sua articulação real com ela seja inconsciente. É esse vínculo entre duas representações verbais em causa que restabelece a discursividade, na medida em que ambas podem ser unidas à mesma formação discursiva (podendo então uma remeter à outra por reformulação parafrástica ou por metonímia). Esse vínculo entre as duas representações procede de uma identificação simbólica $[\ldots]$.

Assim, pensamos que o neoliberalismo é um novo liberalismo, mas entre esses dois regimes, há a prática do capitalismo, tão destacado e discutido por Marx (1993) e Althusser (1985). Trata-se de representações que retornam e ancoram a interpretação e a leitura dessa materialidade, como possibilidade decorrente de imagens e de palavras que encaminham para uma dispersão de textos e estes para o discurso.

Encaminhamo-nos para a análise da segunda materialidade discursiva ${ }^{6}$, que foi produzida por Jota Camelo, reiterando o seu funcionamento como discurso pelo qual ressoam memórias e outros discursos, focados em acontecimentos de um tempo mais próximo. Vale reiterar, também, que o sentido é efeito de um trabalho simbólico sobre a cadeia significante, considerando a história como historicidade. A textualidade, em tela, pode ser lida de acordo com as práticas e com os discursos em torno da reforma da previdência, em que o neoliberalismo retoma e dá visibilidade ao governo e a previdência ao povo - sujeitos coletivos, mostrando que há problemas que afetam a formação social. A materialidade charge foca nesse problema e mobiliza efeitos linguísticos e não verbais, com vistas a dar destaque, no eixo da formulação, ao inusitado que rompe com a norma identificadora (PÊCHEUX, 1997a), fazendo funcionar o equívoco, que encaminha para diferentes efeitos de sentidos.

6 Pode ser acessada pelos links: <https://br.pinterest.com/pin/270990102564913396/> e https://www.humorpolitico.com.br/jota-camelo/geracao-100/ Acesso em 10 de setembro de 2020. 


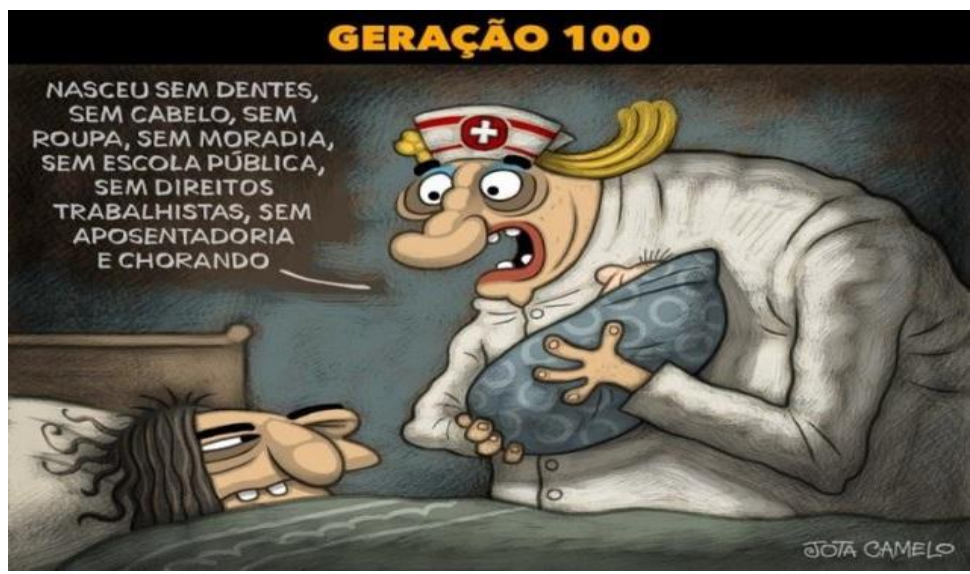

Imagem 2 - Charge de Jota Camelo (2019)

Na esteira da charge (imagem) 1, Neoliberalismo e Previdência, vemos também aqui, na imagem 2, o funcionamento do antagonismo, pelo enunciado "Geração 100", entendendo como antagonismo o embate entre diferentes formações discursivas, notadamente entre a FD dos vulneráveis, mais atingidos pela reforma, e a classe dominante, que pode se beneficiar da reforma. Outro rompimento e possibilidade de o sentido ser outro, decorre da enfermeira, que não é o dominador, mas um sujeito a serviço daquele que detém o poder, situando-se, de certa forma, como um atravessador ou portavoz, que fala em nome $d e$. Inscrita neste lugar, a enfermeira entrega o bebê - que, na ordem do simbólico, está na base imaginária de sujeitos inscritos em uma geração sem direitos.

Como sinalizamos, anteriormente, a enfermeira também se assujeita a um sistema que, como ela - obesa, bem "provida" e forte -, legitima-se pelo sistema capitalista, sinalizando para a contradição decorrente do fato de que o fraco, diante de um ainda mais fraco, torna-se/aparenta ser forte. Entendemos a contradição como o embate dentro de uma mesma formação discursiva, nesse caso, dos sujeitos mais vulneráveis. As cores dos Estados Unidos, no gorro da enfermeira e na sombra dos seus olhos, reforçam esse embate e essa possível leitura, que se sustenta no fato de o país liderar a economia capitalista mundial, inscrevendo o 100 no domínio do que é positivo, sinalizando para sem defeitos, sem problemas, com direitos sociais e uma economia estável. O encaminhamento do 100 para a negação, instaurando a quebra da regularidade discursiva, advém da enumeração, de tudo o que é negado ao recém-nascido, que nasce sem dentes, sem cabelo, sem roupa, sem moradia, sem escola pública, sem direitos trabalhistas, sem aposentadoria e chorando, isto é, SEM nada. O choro pode instaurar diferentes efeitos de sentidos, dentre eles, a desolação, o desespero ou a resistência em que o "choro" pode significar a tentativa de alterar a realidade que se apresenta a "Geração 100".

A leitura/interpretação/compreensão dessa materialidade significante não é literal, considerando-se que, do lado do analista de discurso, não há preocupação com o conteúdo na interpretação de uma materialidade significante. $\mathrm{O}$ analista investe na descrição, com vistas a construir um objeto discursivo, explicitando gestos de interpretação, que desnaturalizam o já dado. O que o analista busca realizar é o batimento entre a descrição, teoria e análise. Este funcionamento, em charges, realiza-se por meio da crítica social que significa a partir do liberalismo, do capitalismo e do neoliberalismo, que retornam como memória e como discursos em circulação, mesmo não estando citados na materialidade, em tela. 
A possibilidade de deslocar o "100" do seu lado positivo, advém do retorno desses regimes econômicos, por meio de discursos que abarcam o social e o político. Trata-se de redes parafrásticas, constituídas pelos discursos que fazem furos e por memórias que ancoram essas redes, instaurando a discursividade. Vale destacar que o '100', que vem da língua, enquanto imaginário linguístico, decorre, de acordo com Pêcheux (1997a, p. 175), "das evidências lexicais inscritas na estrutura da língua", que mobilizam um real "estranho à univocidade lógica, e um saber que não se transmite, não se aprende, não se ensina, e que, no entanto, existe produzindo efeitos" (PÊCHEUX, 2002, p. 43).

Nesse movimento discursivo, a materialidade, em tela, a partir das condições de produção que antecedem a reforma da previdência, mostram que há o deslocamento da expressão "100" para um funcionamento metonímico, em que discursos se atravessam e os interpretamos como relacionados à falta, ao negacionismo, à deriva de memórias, inscritas em domínios distintos. Assim, elas mobilizam o saber discursivo, o interdiscurso, como o espaço em que todos os sentidos estão postos, mas nem todos retornam. $\mathrm{O}$ número $\mathrm{CEM}$ inscreve-se na formação discursiva que se antagoniza com a palavra "SEM", ressoando, por esta última, a ausência, a negação de qualquer possibilidade de direitos sociais mínimos. A leitura discursiva dessa materialidade significante se faz pelos dois movimentos de linguagem, descritos por Orlandi (1987), como decorrentes da articulação de dois processos: o parafrástico e o polissêmico. Isto é, de um lado, há um retorno constante a um mesmo dizer sedimentado - a paráfrase - e, de outro, no texto ocorre uma tensão que aponta para o rompimento, para sentidos outros, referendando que a paráfrase se esburaca e encaminha para a polissemia.

A repetição marca o retorno de práticas ao mesmo espaço do dizer: a reforma, inscrita em um regime de governo neoliberal, no qual os saberes e dizeres inscrevem-se em discursos que mesclam os ideais do liberalismo e do capitalismo. No entanto, a repetição, ao mesmo tempo que reforça o que é dito, dá visibilidade para o equívoco ponto em que o impossível (linguístico) vem aliar-se à contradição (histórica); o ponto em que a língua atinge a história (GADET e PÊCHEUX, 2004, p. 64). Destacamos, com isso, a ressignificação dos dois regimes anteriores, que apagam/rompem com determinadas práticas e agregam/fazem funcionar outras. Vemos que um novo liberalismo e um novo capitalismo retornam ao eixo da formulação pelo discurso transverso, em que discursos e domínios distintos, de acordo com Pêcheux (1997), se atravessam, vindos de tempos e de lugares distintos. Com isso, instauram uma nova representação: a do neoliberalismo, como uma prática pautada na dominação, em que os vulneráveis são como criança recém-nascida, constituída como SEM, contradizendo-se, opondo-se/rompendo com o 100 (CEM).

Com isso, instaura-se a discursividade, como a manifestação da relação entre o homem e o mundo (a natureza, a sociedade, o outro), manifestação da prática de linguagem, como a perda de direitos sociais. O rompimento da cadeia significante sinaliza para o fato de que, desde o nascimento, a criança é um sujeito SEM. No entanto, ela pode ser um sujeito 100, no sentido positivo, já que ainda não se filia a nenhuma formação discursiva. A posição da mãe acuada permite entender que ela se filia ao lado dos SEM, e a enfermeira está a mando/submetida aos CEM, daqueles que representam o capitalismo dominador. A mãe é o povo já submetido. 
É nessa relação entre o dito e o não-dito, o que pode e deve ser feito, que se constituem redes parafrásticas e a possibilidade de os mecanismos de diferenciação interna das FDs, fazendo 'furos' e constituindo efeitos de sentido no interior/exterior. Com isso, a repetição se esvai e instaura a polissemia, a fuga dos sentidos, conforme Orlandi (2004). Em resumo: o enunciado "Geração dos 100" encaminha para o duplo funcionamento do interdiscurso, destacados por Venturini (2009), como sendo o intradiscurso e o pré-construído. Assim, a "Geração 100" pode ser aquela desprovida de saúde pública, de moradia, de aposentadoria, entre outras faltas, podendo ser significada como a geração anestesiada, fazendo eco com o que diz Pêcheux (2011, p. 92), em relação ao sistema que possui "a arte de anestesiar as resistências, de absorver as revoltas no consenso e de fazer abortar as revoluções”.

A terceira charge ${ }^{7}$ continua essa discussão sobre a reforma da previdência e as nuances capitalistas/neoliberais. A análise dessa charge demanda deslocar os sujeitos empíricos para a posição discursiva, em que o mágico não é Bolsonaro, presidente do Brasil, mas um Estado inscrito no regime neoliberalista, que se abstém do dever de apoiar e de defender os chamados 'vulneráveis'. Estes, além de não serem amparados, não vão receber o retorno das contribuições pagas ao Estado, por pelo menos quarenta anos de vida. Do mesmo modo, o que está sendo 'fatiado' não é o idoso, mas o vulnerável, aquele que está no lugar do povo, representando não o todo, mas a parcela de explorados. $\mathrm{O}$ mágico, certamente, possui uma técnica e lugares específicos bem marcados, onde 'pode' e 'deve' cortar. Na textualidade, em tela, constitui-se o efeito de sentido de que o 'mágico' está cortando demais, sem respeitar os limites esperados/marcados. Desse modo, esse sujeito vai 'matar' aquele que está na caixa - o aposentado (povo) -, que perde parcela grande de seus direitos e não terá como sobreviver. Aquele que está na caixa representa discursivamente o povo.

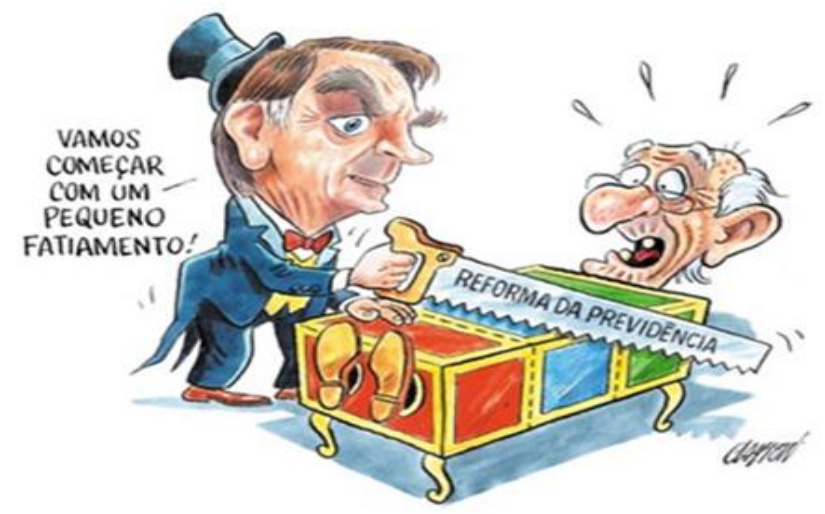

Imagem 3 - Charge do Clayton (2018)

Entendemos que, no jogo da língua na história, a palavra 'pequeno' perde seu efeito, considerando que o corte se faz em quase $50 \%$ da caixa mágica, desrespeitando o limite que já está marcado. A quebra da regularidade decorre especialmente dessa palavra, quando se pode observar que o fatiamento é grande, podendo-se perguntar, ainda, de que tamanho seria um 'fatiamento' maior. A primeira investida ocorreu pela Emenda Constitucional 103/2019, que aprova o pagamento de alíquotas progressivas para a

7 Pode ser acessada pelo link: 〈http://blogdoeliomar.com.br/2018/12/06/a-charge-do-clayton-1059/〉. Acesso em: 10 set. 2020. 
previdência, exigindo a continuidade de contribuição, também dos já aposentados. Esses sujeitos não 'perdem' somente direitos, perdem também o que já possuíam, por direito adquirido. No que tange aos funcionários públicos, há questionamento em torno de cobranças extraordinárias de contribuição, apagando o fato de que esses sujeitos são bastante prejudicados pelo fatiamento que objetiva resolver o problema da previdência.

As alterações, aprovadas nessa reforma da previdência social, foram alvo de ações diretas de inconstitucionalidade, no Supremo Tribunal Federal $(\mathrm{STF})^{8}$, por desrespeito à Constituição em vigor no Brasil. Além de propor o aumento progressivo de contribuição, há desrespeito às regras de transição e ao direito adquirido. O deslocamento de um acontecimento inscrito no domínio do espetáculo para um acontecimento inscrito na prática social brasileira faz ressoar a crítica social. Por um lado, o presidente, assim como o mágico, deve considerar que o desrespeito aos limites de realização do corte pode provocar dano grave aos sujeitos e à formação social. Por outro lado, a aproximação entre o mágico e o proponente das reformas, e entre o idoso e a moça bonita, que participa dos espetáculos circenses, constrói redes parafrásticas em torno de vida e de morte, do respeito/desrespeito.

Por esse funcionamento, a charge, como uma textualidade, investe em diferentes domínios do saber, trazendo-os para o eixo da formulação e fazendo-os funcionar no limite entre o simbólico e o real, provocando a tensão e a reinscrição do dizer em outra ordem. Nesse limiar, o mágico passa a ser aquele que, no lugar do riso, provoca o medo, pelos cortes que realiza. Dentro da caixa, estaria uma moça bonita e sorridente, que dá lugar a um idoso tomado pelo medo, devido às incertezas em relação ao futuro. Vale contrapor, também, as palavras 'FATIAMENTO' e 'CORTE', considerando-se Pêcheux (1997a), para quem os sentidos não são literais, mas dependentes da inscrição a sujeitos e das posições assumidas por eles, conforme Orlandi (2002), quando destaca que as palavras não são indiferentes aos sentidos. Assim, $\operatorname{cortar}^{9}$ significa dividir em partes, podendo ser um verbo transitivo em que se corta algo ou alguém e, intransitivo, quando possui sentido completo, significando cortar igual a fatiar. Já, fatiar, significa dividir pedaços em partes, geralmente pequenas, sendo possível aproximar de retirada, supressão, pagamento de tributo.

\section{CONSIDERAÇÕES FINAIS}

A proposta deste artigo contempla a leitura de charges, entendendo-as como materialidade discursivas, tendo em vista as relações que elas estabelecem entre domínios de saber, fazendo funcionar esses domínios na ordem do discursivo, aproximando e distanciando o acontecimento de sua inscrição na história. Este funcionamento joga, ao mesmo tempo, com o saber que vem destes diferentes domínios, destacando-se que a primeira textualidade se inscreve no domínio do político e da economia, fazendo ressoar práticas sociais de exploração. A segunda joga com oposições que decorrem da língua, mas não só, tendo em vista que estas oposições instauram acontecimentos, os quais convocam memórias e as reorganizam em discurso (PÊCHEUX, 2002, p. 19).

\footnotetext{
${ }^{8}$ Disponível em: <https://stf.jusbrasil.com.br/noticias/782339342/stf-recebe-as-primeiras-acoes-contra-areforma-da-previdencia $>$. Acesso em: 20 mai. 2020.

${ }^{9}$ Disponível em: <https://dicionario.priberam.org/cortar>. Acesso em: 20 mai. 2020.
} 
Nessa materialidade, o neoliberalismo representa-se pela metáfora da bota, pela qual ressoa o militarismo e o achatamento do Sistema Previdenciário, achatando-o e, possivelmente, fazendo-o se tornar ineficiente ou com dificuldade de funcionamento. Já a segunda, que também segue nessa direção, faz o jogo entre 100 (sentido positivo) e SEM, encaminhando para a ausência e, nesse contexto, para a retirada de direitos. O sentido positivo está no dominador, e o SEM, em que ressoa a falta, está no dominado, no caso, na mãe e, especialmente, na criança, incapaz de resistir, de mudar a ordem social. A terceira materialidade também trata da Reforma/Neoliberalismo, fazendo uma crítica à previdência, mobilizando e fazendo funcionar a recreação por meio da mágica com a Reforma da Previdência. Com isso, há deslocamentos de sentidos, rompendo com as regularidades e colocando, em um mesmo eixo, o riso, a brincadeira com vida/morte, as perdas/retiradas de direitos.

A Charge 1 sinaliza para o discurso da política neoliberal, ressoando Pinochet e a reforma da previdência, realizada em 1981, apontando para a não participação do Estado na economia, na livre negociação, no embate entre patrões e empregados, e isso não está sendo dito na materialidade discursiva. O governo é representado, na charge, pelo neoliberalismo e pela reforma da previdência, que atinge o povo. Tal fato envolve a interpretação de acontecimentos que podem estar filiados a diferentes formações discursivas. $\mathrm{O}$ humor presente, nessa discursividade, muitas vezes, mascara e apaga o funcionamento ideológico, fazendo com que o sujeito ria da sua própria desgraça, de modo que a charge esconde e sugere sentidos outros.

A Charge 2 propõe, enquanto materialidade discursiva, um jogo de sentidos em que o discurso institui um mosaico daquilo que já foi dito e ressoa como pré-construído, com discursos que vêm da história e significam pela língua, pelo que é mobilizado por meio da enfermeira, da criança, da mãe e das palavras que complementam o SEM. Segundo Landowski (1995, p. 81), a charge nos permite "ler o espetáculo do mundo que o jornal nos oferece".

Finalmente, as Charges 1 e 2 e a materialidade discursiva da Charge 3 apontam para a imagem e a fala/língua que significam. O presidente, em sua posição-sujeito, traz o discurso da economia de mercado, do capital, do neoliberalismo, como identificado na Charge 1. A imagem do idoso, sendo cortado ao meio, faz retornar o passado, instaurando efeitos de sentidos que desestabilizam, deslocam imaginários em torno do mágico, do idoso, do espetáculo e do riso.

Por fim, vale destacar que a leitura não encaminha para a literalidade dos sentidos e nem para conteúdos em torno da temática. Na Análise de Discurso, ela desloca, subverte o real, joga com os sentidos, com a língua na história e também com imagens, que comportam nelas mesmas as memórias e os discursos e se inscrevem na discursividade, significando pelo que retorna a partir delas/por elas. Enfim, as três materialidades, enfocam a mesma temática: a reforma da previdência e se inscrevem em práticas sociais, trazendo a reprodução/transformação/identificação de sujeitos, com o que lhes é dado a ver e a ler, conforme Pêcheux (2002). 


\section{REFERÊNCIAS}

ADGHIRNI, Zélia Leal. Quando a charge mata. Mídia\&Política. Universidade de Brasília, 1999. Disponível em <http://www.midiaepolitica.unb.br>. Acesso em 05 mai. 2020.

ALTHUSSER, Louis. Aparelhos ideológicos de Estado. 7. ed. Rio de Janeiro: Graal, 1985.

BARONAS, Roberto Leiser; AGUIAR Gisele Freitas de. Do acontecimento histórico ao acontecimento discursivo: o político na charge. REVISTA BAKHTINIANA, Instituição responsável pela publicação, São Paulo, Editora, p. 165-182, v. 1, n. 2, 2009. Disponível em: 〈>; acesso em 10 de agosto de 2020.

FLÔRES, Onici. A leitura da charge. Canoas: Ulbra, 2002.

GADET, Françoise; PÊCHEUX, Michel. A língua inatingível: O discurso na história da linguística. Campinas, SP: Editora RG, 2004.

HERBERT, Thomas. Reflexões sobre a situação teórica das ciências sociais e, especialmente, da Psicologia Social. In: Pêcheux M. Análise de Discurso: Michel Pêcheux. Textos selecionados por Eni Puccinelli Orlandi. 2a ed. Campinas: Pontes; 2011 [1966].

LAGAZZI, Suzy. Linha de Passe: materialidade significante em análise. REVISTA RUA, Instituição responsável pela publicação, Campinas/SP, Editora, página inicial do artigo-página final do artigo, v. 16, n. 2, 2010. Disponível em: ২>; acesso em 16 de agosto de 2020.

LANDOWSKI, Eric. Não se brinca com o humor: a imprensa política e suas charges.

Revista FACE. São Paulo: EDUC, v.4, n.2, p. 64-95, jul./dez.1995.

ORLANDI, Eni. A linguagem e seu funcionamento: as formas do discurso. 2. ed. Campinas, SP: Pontes, 1987.

ORLANDI, Eni. Discurso e texto: formulação e circulação dos sentidos. Campinas/SP: Pontes Editores, 2001.

ORLANDI, Eni. Análise do discurso: princípios e procedimentos. 4. ed. Campinas, SP: Pontes, 2002.

ORLANDI, Eni. Interpretação: autoria, leitura, efeitos sobre o trabalho simbólico. Campinas/SP, Pontes Editores, 2004.

ORLANDI, Eni. Documentário: acontecimento discursivo, memória e interpretação. In ZANDWAIS, Ana; ROMÃO, Lucília Maria Sousa. Leituras do político. Porto Alegre: Editora da UFRGS, 2011.

PÊCHEUX, Michel. Semântica e discurso: uma crítica à afirmação do óbvio. Campinas: Editora da Unicamp, 1997a.

PÊCHEUX, Michel. Análise automática do discurso (AAD-69). In: GADET, Françoise; HAK, Tony. (Org.). Por uma análise automática do discurso: uma introdução à obra de Michel Pêcheux. 2. ed. Campinas, SP: Unicamp, p. 61-105, 1997b.

PÊCHEUX, Michel. O papel da memória. Trad. Horta Nunes. In: ACHARD, Pierre. O papel da memória. Campinas/SP: Pontes Editores, 1999.

PÊCHEUX, Michel. Discurso: estrutura ou acontecimento. Trad. Eni Orlandi. 3 ed. Campinas, SP: Pontes Editores, 2002.

PÊCHEUX, Michel. Foi "propaganda" mesmo que você disse? In: ORLANDI, Eni. Análise de Discurso: Michel Pêcheux. Textos escolhidos: Eni Orlandi. Campinas, SP Pontes Editores, 2011.

PETRI, Verli. O funcionamento do movimento pendular próprio às análises discursivas na construção do "Dispositivo experimental" da Análise de Discurso. In: PETRI, Verli; 
DIAS, Cristiane. Análise de Discurso em perspectiva: teoria, método e análise. Santa Maria/RS: Editora da UFSM, p. 39-48, 2013.

PILLA, Armando; QUADROS, Cynthia Boos de. Charges: uma leitura orientada pela Análise do Discurso. LINGUAGENS - REVISTA DE LETRAS, ARTES E COMUNICAÇÃO, Instituição responsável pela publicação FURB, Blumenau, Editora, p. 226-239, v. 3, n. 3, 2009. Disponível em: https://proxy.furb.br/ojs/index.php/linguagens/article/view/1497/0; acesso em 15 de agosto de 2020.

VENTURINI, Maria Cleci. Imaginário Urbano: espaço de rememoração/comemoração. Passo Fundo: Editora da UPF (Universidade de Passo Fundo), 2009.

ZANDWAIS, Ana. Possíveis leituras de "Foi propaganda mesmo que você disse?, de Michel Pêcheux. REVISTA CONEXÃo LETRAS, (UFRGS), Porto Alegre, Editora da UFRGRS, p. 69-79, v. 14. n. 22, 2009. Disponível em: https://seer.ufrgs.br/conexaoletras/article/view/98121, acesso em 20 de julho de 2020.

Artigo recebido em: mai. de 2020.

Aprovado e revisado em: out. de 2020.

Publicado em: dez. de 2020.

Para citar este texto:

MOREIRA, José Carlos; VENTURINI, Maria Cleci. A Leitura na Perspectiva Discursiva: o político e a política em charges. Entremeios [Revista de Estudos do Discurso, ISSN 2179-3514, on-line, www.entremeios.inf.br], Seção Estudos, Programa de Pós-Graduação em Ciências da Linguagem (PPGCL), Universidade do Vale do Sapucaí (UNIVÁS), Pouso Alegre (MG), vol. 22, p. 70-86, jul. - dez. 2020.

DOI: http://dx.doi.org/10.20337/ISSN2179-3514revistaENTREMEIOSvol22pagina70a86 